\title{
Relationship of Scoliosis with Pain and Respiratory Dysfunction in Patients with Duchenne Muscular Dystrophy
}

\author{
Filiz Meryem Sertpoyraz ${ }^{1}$ Bedile Irem Tiftikcioglu ${ }^{2}$ \\ Nihan Erdinc Gunduz ${ }^{5}$ Aylin Dikici ${ }^{5}$ Yasar Zorlu ${ }^{6}$ \\ ${ }^{1}$ Department of Physical Medicine and Rehabilitation and \\ Neuromuscular Unit, Izmir Training and Research Hospital, Health \\ Science University, Izmir, Turkey \\ 2 Department of Neurology, Baskent University Faculty of Medicine, \\ Zubeyde Hanim Research and Practice Hospital, Izmir, Turkey \\ ${ }^{3}$ Department of Pediatric Neurology and Neuromuscular Unit, Izmir \\ Training and Research Hospital, Health Science University, Izmir, Turkey \\ ${ }^{4}$ Department of Neuromuscular Unit, Izmir Training and Research \\ Hospital, Health Science University, Izmir, Turkey \\ ${ }^{5}$ Department of Physical Medicine and Rehabilitation, Izmir Training \\ and Research Hospital, Health Science University, Izmir, Turkey \\ ${ }^{6}$ Department of Neurology and Neuromuscular Unit, Izmir Training \\ and Research Hospital, Health Science University, Izmir, Turkey
}

\author{
Figen Baydan ${ }^{3}$ Bakiye Tuncay ${ }^{4}$
}

\author{
Address for correspondence Filiz Meryem Sertpoyraz, MD, \\ Department of Physical Medicine and Rehabilitation and \\ Neuromuscular Unit, Izmir Training and Research Hospital, Health \\ Science University, Izmir, Turkey Guney Mahallesi, 1140/1 Sokak. \\ No: 1, Yenisehir, Konak, 35180 Izmir, Turkey \\ (e-mail: dr.fms70@gmail.com).
}

\begin{abstract}
Keywords

- Duchenne muscular dystrophy

- pain

- scoliosis

- respiratory dysfunction

Introduction Scoliosis is one of the major causes of respiratory dysfunction in patients with Duchene muscular dystrophy (DMD). Also, progressive spinal deformity severely affects walking and sitting, and can also lead to pain and difficulty in patient care. Although the relationship between scoliosis and respiratory functions was extensively studied, its impact on pain has not been examined. Hereby, we aimed to evaluate the relationship between scoliosis and respiratory dysfunction and pain, together with the frequency of scoliosis in Turkish DMD patients.

Materials and Methods The demographical data, rate, and region of scoliosis, pain, and respiratory functions were evaluated in 69 male DMD patients. The severity of pain was evaluated with a visual analog scale (VAS) and the degree of scoliosis was assessed with Cobb angle. Forced vital capacity was used to grade the pulmonary functions.

Results Scoliosis was present in $52.2 \%$ of the patients, mainly in the dorsolumbar region. Pain was present in $53.6 \%$ of the patients, most commonly in the back and lumbar regions. The rate of pulmonary dysfunction was $49.3 \%$. Of the 36 patients with scoliosis, prevalences of pain and respiratory dysfunction were 77.7 and $50.0 \%$, respectively. Scoliosis was significantly associated with pain and respiratory dysfunction, as expected.

Conclusion The prevalence of pain and respiratory dysfunction is considerably high in DMD patients with scoliosis. These patients should be closely monitored for pain and deterioration in respiratory functions, to ease their daily care, increase their quality of life, and preserve the functionality, as long as possible.
\end{abstract}

received

June 10, 2019

accepted after revision

October 28, 2019

published online

December 4, 2019
Copyright $\odot 2020$ by Georg Thieme

Verlag KG, Stuttgart . New York
DOI https://doi.org/

10.1055/s-0039-3400971. ISSN $1304-2580$. 


\section{Introduction}

Scoliosis is the deformity of the spine in the coronal plane and defined as a curvature of more than 10 degrees. It is often associated with the pelvic inclination and is accompanied by kyphosis. Neuromuscular scoliosis has been reported to be as high as 85 to $90 \%$ in Duchene muscular dystrophy (DMD). It is a progressive condition that impairs mobility, gait, sitting and balance, trunk stability, cardiac and pulmonary functions, and inevitably results in severe disability in daily living activities. Also, scoliosis causes pain in varying intensities, which eventually increases the morbidity. ${ }^{1}$

Patients with DMD typically have progressive restrictive respiratory deterioration and eventually respiratory failure. Standard of care guidelines recommends intervention in treatment when the percent of predicted forced vital capacity (FVC\%) falls below the clinically relevant thresholds. ${ }^{2}$ Pulmonary function is inversely correlated with patient age and severity of scoliosis in DMD. ${ }^{1}$

Pain is another symptom that significantly affects physical and mental wellbeing. Mechanical factors have been suggested as the cause of pain in DMD. ${ }^{3}$ Although the relationship between scoliosis and respiratory functions was extensively studied, its impact on pain has not been examined, particularly. Hereby, we aimed to evaluate the relationship between scoliosis and respiratory dysfunction and pain, and the frequency of scoliosis in a group of Turkish DMD patients.

\section{Materials and Methods}

\section{Study Population}

This study was conducted on pediatric patients registered in neuromuscular diseases unit at Izmir Tepecik Education and Research Hospital, who were admitted between January and August, 2018. Inclusion criteria were (1) having a definite diagnosis of DMD with clinical, laboratory, muscle biopsy and/or genetic testing, (2) age between 8 and 18 years, (3) able to give informed consent to participate in the study. Exclusion criteria were diagnosed with a non-DMD myopathy, having active respiratory tract infection, being on mechanical ventilation, having mental retardation, or having any malignant, infectious, or rheumatologic disease, or having a vertebral fracture that could cause spinal pain. The lower limit of the age range was set based on the rare occurrence of scoliosis in DMD under the age of 8 , and the difficulty to assess respiratory function tests in young children. Patients older than 18 were excluded since the study targets the pediatric age group.

A total of 150 DMD patients were enrolled. All were male. Fifty patients were excluded for being under the age of 8 years and 14 patients for being above the age of 18 years. Nine patients could not perform the pulmonary function test (PFT). Scoliosis radiography could not be performed in one patient. One patient had mental retardation, one patient had a vertebral fracture, three had prior spinal surgery, and one had active respiratory tract infection. Eventually, 69 patients were included in the study.
Demographical data including age, age at diagnosis, disease duration, consanguinity, as well as clinical features, including corticosteroid therapy, ambulation, assisted device or wheelchair use were noted. Height measurements could not be performed in the whole patient group, because scoliosis, contractures, and joint stiffness significantly affect height.

Therefore, height, weight, and body mass index were not included in the analyses. All patients were receiving prednisolone therapy at a dose of $0.75 \mathrm{mg} / \mathrm{kg} / \mathrm{d}$. Patients were grouped according to the classification by DMD Care Considerations Working Group at TREAT-NMD neuromuscular network as follows: stages 1,2 , and 3 were considered ambulatory, stages 4 and 5 nonambulatory. ${ }^{4}$

This study was conducted according to the Helsinki declaration and all patients or their parents gave informed consent for inclusion in this study. The local ethics committee approved the study protocol.

\section{Assessment of Scoliosis}

Scoliosis was assessed through clinical and radiological examinations. The presence and the region of scoliosis (cervical, dorsal, dorsolumbar, and lumbar) were recorded. Anteroposterior and lateral scoliosis radiographs were taken. Care was taken to include the entire spine from the cervical vertebrae to the hip joints in anteroposterior radiographs. The radiographs of patients, who could not stand up, were taken in a sitting position without support. The upper end was positioned at the ear level, shoulders at 90 degrees flexion, hands-on shoulders, and elbows at maximum flexion. The degree of scoliosis was graded using the Cobb angle measured by a radiologist, which is the "gold standard" of scoliosis evaluation. It is the angle formed between the two lines drawn along the end plates of the terminal vertebrae at both ends of the curve deformity, whose end plates are most tilted toward each other. Cobb angle less than 30 degrees was defined as mild scoliosis, angles between 31 and 50 degrees as moderate scoliosis, and angles greater than 50 degrees were scored as severe scoliosis. ${ }^{5}$

\section{Assessment of Respiratory Functions}

Respiratory functions were evaluated with a spirometer device (Medical International Research; Rome, Italy). Spirometric measurement was performed 2 hours after the meal with the patient in a relaxed and comfortable position. Patients were informed about the test, at first.

Forced vital capacity (FVC), which is the volume of air forcibly exhaled during fast and deep expiration after the deepest inspiration possible, was measured to evaluate restrictive type pulmonary dysfunction. Restrictive respiratory disorder was graded according to the FVC rate, as normal (FVC $\geq 81 \%$ ), mild (66-80\%), moderate (51-65\%), or severe ( $\leq 50 \%)^{6}$

\section{Assessment of Pain}

The presence and the location (neck, back, waist) of spinal pain were mapped. Pain intensity was assessed with a visual analog scale (VAS). Pain was categorized as mild (VAS $<4$ ), moderate $(4 \leq \mathrm{VAS}<7)$, or severe (VAS $\geq 7){ }^{7}$ Patients were instructed not to take any analgesic/pain killers within 24 hours before the evaluation. 


\section{Statistical Analysis}

Statistical analyses were performed with SPSS v20.0 for Mac (SPSS Inc.; Chicago, United States).

Descriptive data were expressed as percentages. Student's $t$-test or chi-square test was used to compare groups concerning numerical or categorical data, respectively. Correlation analyses were performed using the Spearman rho correlation test. The level of significance according to the Spearman rho correlation test was determined as follows: $r=0.90$ to 1.00 very high; $r=0.70$ to 0.90 , high; $r=0.50$ to 0.70 , moderate; $r=0.30$ to 0.50 , low; $r=0.00$ to 0.30 negligible correlation. ${ }^{8}$ The statistical significance level was set at $p<0.05$.

\section{Results}

The mean age was $12.10 \pm 4.05(8-18)$ years and the mean age at diagnosis was $7.24 \pm 4.87(1-11)$ years. Consanguinity frequency was $19.7 \%(n=12)$. Clinical features of DMD patients are summarized in -Table 1. The incidence of scoliosis increased with age. A significant and low positive correlation was found between patient age and scoliosis $(p<0.001$, rho $=0.445)$.

Thirty-seven patients out of 69 reported pain. The mean VAS score was $3.1 \pm 0.8(2-6)$ and pain was mostly localized to the back. Pain was significantly more common in patients with

Table 1 Clinical features of DMD patients

\begin{tabular}{|l|l|}
\hline & $n(\%)$ \\
\hline Pain & \\
\hline Yes & $37(53.6)$ \\
\hline No & $32(42.4)$ \\
\hline Ycoliosis & $36(52.2)$ \\
\hline No & $33(47.8)$ \\
\hline Scoliosis (age groups) & \\
\hline Age 8-13 & $14(38.8)$ \\
\hline Age 14-18 & $22(61.2)$ \\
\hline Severity of scoliosis & \\
\hline Mild & $29(80.6)$ \\
\hline Moderate & $4(11.1)$ \\
\hline Severe & $3(8.3)$ \\
\hline Region of scoliosis & \\
\hline Lumbar & $12(33.3)$ \\
\hline Dorsal & $4(11.1)$ \\
\hline Dorsolumbar & $20(55.6)$ \\
\hline Ambulation & $32(46.4)$ \\
\hline Yes & $32(46.4)$ \\
\hline No & \\
\hline Wheelchair-bound & \\
\hline Yes & \\
\hline No & \\
\hline
\end{tabular}

Abbreviation: DMD, Duchene muscular dystrophy. scoliosis $(p<0.001)$. Of the 36 patients with scoliosis, 28 $(77.7 \%)$ had pain. However, the mean VAS score was $3.8 \pm 0.51$ in the scoliosis group, whereas $2.86 \pm 0.35$ in the nonscoliosis group. There was no significant difference between these groups in terms of pain severity $(p>0.05)$.

Among the whole study group, 34 patients (49.3\%) had respiratory dysfunction. The mean FVC value of patients with respiratory dysfunction was $73.09 \pm 25.9$.

- Table 2 lists the frequency of respiratory dysfunction in patients grouped for severity and region of scoliosis and severity of pain. Fifty percent of the patients with scoliosis had respiratory dysfunction. The severity of respiratory dysfunction increased with the severity of scoliosis. There was a positive and moderate correlation between scoliosis and respiratory dysfunction $(p<0.001$, rho $=0.569$ ).

There was no significant relationship between the region of scoliosis and respiratory dysfunction $(p>0.05)$.

The severity of pain and the severity of respiratory dysfunction were significantly and moderately correlated $(p<0.001$, rho $=0.624)$.

Thirty-seven patients (53.6\%) were wheelchair-bound; 28 patients (75.6\%) of which had scoliosis. The association between scoliosis and using a wheelchair was also statistically significant $(p<0.001$, rho $=0.411)$.

\section{Discussion}

Pain, mostly in the back and lumbar regions, was a common symptom reported by $53.6 \%$ of the DMD patients in this study. It is noteworthy that, a high number of patients with scoliosis $(77.7 \%)$ had pain $(p<0.001)$. The majority of the DMD patients had scoliosis and were wheelchair bound. Scoliosis was present in the dorsolumbar region most frequently. The severity of scoliosis significantly affected respiratory functions. The majority of the patients with mild scoliosis (62.1\%) had normal FVC; on the other hand, all patients with severe scoliosis had severe respiratory dysfunction (100\%).

Previously, the incidence of scoliosis was reported to be $17 \%$ among patients receiving steroid therapy. ${ }^{9}$ All patients in the present study were on corticosteroid therapy, including the wheelchair-bound ones, because corticosteroid therapy is believed to improve the cardiopulmonary functions and prolongs survival. Since corticosteroids have a positive effect on respiratory functions, patients are recommended to continue the treatment even in the late stages and in the period of ambulation loss. ${ }^{10-12}$ In our study, despite the steroid use, the scoliosis rate was high. As expected, the prevalence of scoliosis increased with age. The progression of scoliosis is accelerated with loss of ambulation. It has been recommended to extend the walking time with appropriate orthoses, which might slow down the progression of scoliosis in DMD patients aged 13 to $15 .^{13}$

Pain is a symptom that significantly reduces the quality of life in DMD, thus etiology should be investigated in detail. ${ }^{14-16}$ In the present study, almost every four out of five DMD patients with scoliosis had pain. Lager and Kroksmark explained the causes of this pain as the loss of ambulation, disruption of 
Table 2 The frequency of respiratory dysfunction in DMD patients grouped for the severity of scoliosis assessed by Cobb angle, the region of scoliosis and severity of pain assessed by VAS

\begin{tabular}{|c|c|c|c|c|c|c|}
\hline & & \multicolumn{5}{|c|}{ Severity of respiratory dysfunction, $n(\%)$} \\
\hline & & Normal & Mild & Moderate & Severe & Total \\
\hline \multirow[t]{4}{*}{ Severity of scoliosis } & Mild & $18(62.1)$ & $4(13.8)$ & $2(6.9)$ & $5(17.2)$ & $29(80.6)$ \\
\hline & Moderate & - & - & $2(50)$ & $2(50)$ & $4(11.1)$ \\
\hline & Severe & - & - & - & $3(100)$ & $3(8.3)$ \\
\hline & Total & $18(50)$ & $4(11.1)$ & $4(11.1)$ & $10(27.8)$ & $36(100)$ \\
\hline \multirow[t]{4}{*}{ Region of scoliosis } & Dorsal & $3(75.0)$ & - & - & $1(25.0)$ & $4(11.1)$ \\
\hline & Lumbar & $7(58.4)$ & $1(8.3)$ & - & $4(33.3)$ & $12(33.3)$ \\
\hline & Dorsolumbar & $6(30.0)$ & $3(15.0)$ & $4(20.0)$ & $7(35.0)$ & $20(55.6)$ \\
\hline & Total & $16(44.4)$ & $4(11.1)$ & $4(11.1)$ & $12(33.3)$ & $36(100)$ \\
\hline \multirow[t]{4}{*}{ Severity of pain in pts. with scoliosis } & Mild & $13(61.9)$ & $2(9.5)$ & $2(9.5)$ & $4(19.0)$ & $21(75.0)$ \\
\hline & Moderate & - & - & $1(16.7)$ & $5(83.3)$ & $6(21.4)$ \\
\hline & Severe & - & - & - & $1(100)$ & $1(3.6)$ \\
\hline & Total & $13(46.4)$ & $2(7.1)$ & $3(10.7)$ & $10(35.7)$ & $28(100)$ \\
\hline
\end{tabular}

Abbreviations: DMD, Duchene muscular dystrophy; VAS, visual analog scale.

posture, and increased weakness affecting spine biomechanics in DMD. ${ }^{17}$ Similarly, mechanical factors, such as pelvic obliquity, which arise with the loss of sitting balance due to scoliosis, asymmetric posture, imbalance in mechanical loading, weakness, and strain in paraspinal muscles, and degenerative changes have also been suggested as the cause of pain in DMD. Also, pain is also accompanied by fatigue, anxiety, and depression in this group of patients. ${ }^{3}$ In accordance, Pangalila et al reported that up to $74 \%$ of the patients with DMD experienced pain, which was accompanied by fatigue, anxiety, and depression. ${ }^{18}$ Zebracki et al evaluated the pain and the effect of pain on daily life activities among children with Duchenne or Becker muscular dystrophy, and reported the co-occurrence of mild to moderate level of pain, most commonly in the lower back region, which was consistent with our findings in the present study. ${ }^{19}$

Furthermore, pain is a common symptom in several other neuromuscular diseases other than DMD. In a study evaluating pain in 862 patients with neuromuscular diseases, it was found that pain was quite frequent comorbidity and there was a significant relationship between pain and poor general health, vitality, and social function. It was also reported that pain was moderately associated with increased fatigue, inability to cope with stress, and sleep disturbances. The limitation of physical abilities contributes to all these problems. $^{20}$

Pulmonary function tests were performed in all patients and $49.3 \%$ had restrictive type dysfunction. Besides, $50 \%$ of the patients with scoliosis had respiratory dysfunction. We found that respiratory dysfunction worsened with the severity of scoliosis. Reduced strength in the respiratory muscles and scoliosis in the thoracic region are the most important causes of deterioration in respiratory function in DMD. Respiratory dysfunction is an important risk factor for lung infections, pulmonary hypertension, and right-sided heart failure. ${ }^{14,17}$
Mullender et al, emphasize that regular monitoring of scoliosis is important for evaluating pulmonary vital capacity. ${ }^{15}$

This study is subject to several limitations. Since a considerable amount of our patients had contractures and scoliosis, height measurements and body mass index could not be assessed and included in the analyses. Second, this study lacks evaluation of the quality of life, mood, and fatigue, which could have improved our understanding of the effects of pain on daily living activities.

In conclusion, scoliosis leads to pain and respiratory dysfunction, two comorbidities affecting DMD patients. Since, pain, respiratory dysfunction, and scoliosis are all closely related and highly frequent in DMD, pain and respiratory functions should be closely monitored, besides scoliosis. Frequent visits would enable the physician to recognize the factors affecting the physical and mental functions, such as pain, scoliosis, and respiratory deterioration, and rearrange the treatment plans and rehabilitation programs promptly, accordingly. This is of importance particularly in case of ambulation loss.

This study confirms the high frequency of pain, scoliosis, and respiratory dysfunction in DMD. It would be important to pay attention to the pain of the patient and to do every effort to relieve and prevent the pain.

\section{Funding}

None.

Conflict of Interest

None declared.

\section{Acknowledgments}

The authors would like to thank Dr. Gulden Diniz and Dr. Berk Ozyilmaz for their valuable contributions to the manuscript. 


\section{References}

1 Kurz LT, Mubarak SJ, Schultz P, Park SM, Leach J. Correlation of scoliosis and pulmonary function in Duchenne muscular dystrophy. J Pediatr Orthop 1983;3(03):347-353

2 Mayer OH, Leinonen M, Rummey C, Meier T, Buyse GM, Group DS; DELOS Study Group. Efficacy of idebenone to preserve respiratory function above clinically meaningful thresholds for forced vital capacity (FVC) in patients with Duchenne muscular dystrophy. J Neuromuscul Dis 2017;4(03):189-198

3 Suk KS, Lee BH, Lee HM, et al. Functional outcomes in Duchenne muscular dystrophy scoliosis: comparison of the differences between surgical and nonsurgical treatment. J Bone Joint Surg Am 2014;96(05):409-415

4 Birnkrant DJ, Bushby K, Bann CM, et al; DMD Care Considerations Working Group. Diagnosis and management of Duchenne muscular dystrophy, part 1: diagnosis, and neuromuscular, rehabilitation, endocrine, and gastrointestinal and nutritional management. Lancet Neurol 2018;17(03):251-267

5 Malfair D, Flemming AK, Dvorak MF, et al. Radiographic evaluation of scoliosis: review. AJR Am J Roentgenol 2010;194(3, Suppl):S8-S22

6 Polat M, Sakinci O, Ersoy B, Sezer RG, Yilmaz H. Assessment of sleep-related breathing disorders in patients with Duchenne muscular dystrophy. J Clin Med Res 2012;4(05):332-337

7 von Baeyer CL, Lin V, Seidman LC, Tsao JC, Zeltzer LK. Pain charts (body maps or manikins) in assessment of the location of pediatric pain. Pain Manag 2011;1(01):61-68

8 Mukaka MM. Statistics corner: a guide to appropriate use of correlation coefficient in medical research. Malawi Med J 2012; 24(03):69-71

9 Alman BA, Raza SN, Biggar WD. Steroid treatment and the development of scoliosis in males with Duchenne muscular dystrophy. J Bone Joint Surg Am 2004;86(03):519-524

10 Manzur AY, Kuntzer T, Pike M, Swan A. Glucocorticoid corticosteroids for Duchenne muscular dystrophy. Cochrane Database Syst Rev 2008;(01):CD003725
11 Balaban B, Matthews DJ, Clayton GH, Carry T. Corticosteroid treatment and functional improvement in Duchenne muscular dystrophy: long-term effect. Am J Phys Med Rehabil 2005;84(11): 843-850

12 Duport G, Gayet E, Pries P, et al. Spinal deformities and wheelchair seating in Duchenne muscular dystrophy: twenty years of research and clinical experience. Semin Neurol 1995;15(01):29-37

13 Rodillo EB, Fernandez-Bermejo E, Heckmatt JZ, Dubowitz V. Prevention of rapidly progressive scoliosis in Duchenne muscular dystrophy by prolongation of walking with orthoses. J Child Neurol 1988;3(04):269-274

14 Oda T, Shimizu N, Yonenobu K, Ono K, Nabeshima T, Kyoh S. Longitudinal study of spinal deformity in Duchenne muscular dystrophy. J Pediatr Orthop 1993;13(04):478-488

15 Mullender M, Blom N, De Kleuver M, et al. A Dutch guideline for the treatment of scoliosis in neuromuscular disorders. Scoliosis 2008;3:14

16 Engel JM, Kartin D, Carter GT, Jensen MP, Jaffe KM. Pain in youths with neuromuscular disease. Am J Hosp Palliat Care 2009;26(05): 405-412

17 Lager C, Kroksmark AK. Pain in adolescents with spinal muscular atrophy and Duchenne and Becker muscular dystrophy. Eur J Paediatr Neurol 2015;19(05):537-546

18 Pangalila RF, van den Bos GA, Bartels B, Bergen M, Stam HJ, Roebroeck ME. Prevalence of fatigue, pain, and affective disorders in adults with Duchenne muscular dystrophy and their associations with quality of life. Arch Phys Med Rehabil 2015;96(07): 1242-1247

19 Zebracki K, Drotar D. Pain and activity limitations in children with Duchenne or Becker muscular dystrophy. Dev Med Child Neurol 2008;50(07):546-552

20 Hunt A, Carter B, Abbott J, Parker A, Spinty S, deGoede C. Pain experience, expression and coping in boys and young men with Duchenne muscular dystrophy-a pilot study using mixed methods. Eur J Paediatr Neurol 2016;20(04):630-638 